\title{
Specific detection of viable Salmonella Enteritidis by phage amplification combined with qPCR (PAA-qPCR) in spiked chicken meat samples
}

\author{
Alejandro Garrido-Maestu ${ }^{\mathrm{a}, *}$, Pablo Fuciños ${ }^{\mathrm{b}}$, Sarah Azinheiro ${ }^{\mathrm{a}}$, Carla Carvalho ${ }^{\mathrm{c}, \mathrm{d}}$, \\ Joana Carvalho ${ }^{\mathrm{a}}$, Marta Prado ${ }^{\mathrm{a}}$ \\ ${ }^{a}$ Department of Life Sciences, Nano4Food Unit, Food Quality and Safety Research Group, Av. Mestre José Veiga s/n, 4715-330, Braga, Portugal \\ ${ }^{\mathrm{b}}$ Department of Life Sciences, Nano4Food Unit, Food Processing Research Group, Av. Mestre José Veiga s/n, 4715-330, Braga, Portugal \\ ${ }^{\mathrm{c}}$ Department of Nanoelectronics Engineering, Nanodevices Research Group, International Iberian Nanotechnology Laboratory, Av. Mestre José Veiga s/n, 4715-330, Braga, \\ Portugal \\ ${ }^{\mathrm{d}}$ Centre of Biological Engineering, University of Minho, Campus de Gualtar, 4710-057, Braga, Portugal
}

\section{A R T I C L E I N F O}

\section{Keywords:}

Bacteriophage vB_SenS_PVP-SE2

qPCR

Phage amplification

Salmonella enteritidis

Chicken

\begin{abstract}
A B S T R A C T
Serovar Enteritidis represents $45.7 \%$ of all Salmonella reported human cases identified in Europe. Additionally, "minced meat and meat preparations from poultry" have a high level of non-compliance, regarding Salmonella regulation.

In the current study, a novel method based on the amplification of the Salmonella bacteriophage vB_SenS_PVPSE2, coupled with real-time PCR (qPCR), was developed and evaluated, for the rapid detection of viable Salmonella Enteritidis in chicken samples. The results obtained indicated that the qPCR method could detect down to $0.22 \mathrm{fg} / \mu \mathrm{L}$ of pure virus DNA and a concentration of viral particles of $10^{3} \mathrm{pfu} / \mathrm{mL}$. After a short bacterial recovery step, the addition of bacteriophages to spiked chicken samples indicated that $8 \mathrm{cfu} / 25 \mathrm{~g}$ could be detected within $10 \mathrm{~h}$, including the time for DNA extraction and qPCR analysis. Additionally, the evaluation of the performance parameters: relative sensitivity, specificity, accuracy, positive and negative predictive values, and index kappa of concordance, obtained values higher than $92 \%$, and the acceptability limit values were within the limits. All these results demonstrate that the proposed methodology is a powerful tool for the rapid detection of viable Salmonella Enteritidis.
\end{abstract}

\section{Introduction}

The genus Salmonella comprises two species (Salmonella enterica and Salmonella bongori) and more than 2500 different serovars (Grimont \& Weill, 2007). This genus is one of the most common foodborne pathogens worldwide, as highlighted by the fact that in 2015, 94625 cases of salmonellosis were reported in Europe, representing about $28 \%$ of all reported foodborne diseases in Europe, and a 1.9\% increase with respect to 2014; furthermore, ten member states reported 126 fatal cases (EFSA and ECDC, 2017).

It has been extensively reported that the traditional methods for the detection of foodborne pathogens are lengthy and laborious. For instance, those described by the International Organization for Standardization (ISO) and the Bacteriological Analytical Manual (BAM) from the U.S. Food and Drug Administration (Andrews, Jacobson, \& Hammack, 2011; ISO, 2003) require several hands-on steps over several days (from three to six with confirmation). Against the classical approaches, molecular methods have arisen as fast and reliable alternatives. Focus has been put mainly on those based on nucleic acids amplification, such as the Polymerase Chain Reaction or the real-time PCR (PCR/qPCR, (Chapela, Garrido-Maestu, \& Cabado, 2015)), and more recently those based on isothermal amplification such as Loopmediated isothermal amplification (LAMP, (D'Agostino, Diez-Valcarce, Robles, Losilla-Garcia, \& Cook, 2015)), Ligase Chain Reaction (LCR (Jang et al., 2003),), or Recombinase Polymerase Amplification (RPA, (Kim \& Lee, 2016)). However, a drawback commonly attributed to these techniques is their incapacity to differentiate between viable and non-viable microorganisms. Efforts to overcome this limitation have resulted in the development of alternative approaches that lead to the specific detection of viable bacteria, such as amplification coupled with propidium monoazide (PMA) treatment, RNA amplification, or specific sample treatments to eliminate non-viable microorganisms, thus allowing the direct application of conventional nucleic acid amplification techniques (D'Urso et al., 2009; Feng et al., 2016; Zhang, Brown, \&

\footnotetext{
* Corresponding author.

E-mail address: alejandro.garrido@inl.int (A. Garrido-Maestu).
} 
González-Escalona, 2011).

An entirely different approach for the assessment of bacterial viability was reported by Stewart at al., (Stewart et al., 1998), who developed the Phage Amplification Assay (PAA), in which the bacterial viability is inferred from the observation of phage plaques within a bacterial lawn, after incubating a sample containing the target bacteria with a high titer of a suitable bacteriophage.

(Bacterio)phages are viruses that specifically infect bacteria and thus have been considered exceptional tools for pathogen detection. Also, their lytic cycle usually takes only $1-2 \mathrm{~h}$, and their multiplication within the cell works as an "enrichment" step allowing to shorten detection times (Schmelcher \& Loessner, 2014).

The combination of PAA with qPCR has been reported previously for the detection of Bacillus anthracis and Ralstonia solanacearum (Kutin, Alvarez, \& Jenkins, 2009; Reiman, Atchley, \& Voorhees, 2007). However, it has not been explored in depth for the detection of foodborne pathogens; thus, the aim of the present study was to develop and evaluate a fast method based on PAA-qPCR for the detection of viable Salmonella enterica serovar Enteritidis (SE) in chicken samples.

\section{Materials and methods}

\subsection{Bacterial strains, bacteriophage and culture media}

Salmonella Enteritidis S1400 a wild strain isolated from poultry, that belongs to the private collection of the University of Bristol (Sillankorva et al., 2010), was selected as the reference strain For sample pre-enrichment, as well as for bacterial dilutions, Buffered Peptone Water (BPW, Biokar diagnostics S.A., France) was used. Regarding solid media, SE was plated on Luria-Bertani agar (LB, Sigma-Aldrich, St. Louis, USA). All enrichments, and plate incubation steps were performed at $37{ }^{\circ} \mathrm{C}$ overnight unless otherwise specified.

Confirmation of the presence of $S E$ in spiked food samples after preenrichment, was performed by streaking the pre-enriched samples on Xylose Lysine Desoxycholate Agar (XLD, Biokar diagnostics S.A., France). The plates were incubated at $37^{\circ} \mathrm{C}$ overnight.

The Salmonella phage vB_SenS_PVP-SE2 (GenBank accession no. MF431252.1), previously named $\phi 38$, isolated by Sillankorva et al., (Sillankorva et al., 2010), was chosen for the method. To determine phage concentrations (pfu/mL), ten-fold serial dilutions prepared in SM buffer $\left(100 \mathrm{mM} \mathrm{NaCl}, 50 \mathrm{mM}\right.$ Tris, $8000 \mathrm{mM} \mathrm{MgSO}_{4} \cdot 7 \mathrm{H}_{2} \mathrm{O}, \mathrm{pH} 7.5$ ) were performed. Then $5 \mathrm{~mL}$ of molten semi-solid LB $(7.5 \mathrm{~g} / \mathrm{L}$ agar) containing $100 \mu \mathrm{L}$ of an overnight culture of $S E$ and $100 \mu \mathrm{L}$ of the corresponding phage dilution were poured on solid LB. These plates were incubated at $37^{\circ} \mathrm{C}$ overnight.

\subsection{Primer and probe design}

Sequences from the receptor-binding protein (RBP) region of Salmonella spp. phages were obtained from the GenBank, downloaded and aligned with CLC Sequence Viewer (C L C Bio-Qiagen, 2016). The consensus sequence was chosen for primer/probe design with Primer 3 (Untergasser et al., 2012). All primers and probes were purchased from Integrated DNA Technologies (IDT, Integrated DNA Technologies Inc., Leuven, Belgium) and Sigma-Aldrich (Sigma-Aldrich, St. Louis, USA). RBP-F: CCGAACAACAGTCTCACCGA, RBP-R: CTACAATTTTACCGGCG GCG, RBP-P: ${ }^{56-F A M}$ AACAACAAG/ ${ }^{\text {ZEN } / G C G C G C C C G T A C G A ~}{ }^{3 I A B k F Q}$ (IABkFQ and ZEN are a fluorophore and a quencher, respectively, are Trademarks of IDT).

\subsection{DNA extraction}

A simple thermal lysis DNA extraction protocol was selected for ease of use and rapidity. Briefly, $1 \mathrm{~mL}$ of the pre-enriched sample was taken, heated with agitation $(1400 \mathrm{rpm})$ at $99^{\circ} \mathrm{C}$ for $10 \mathrm{~min}$ in a Thermomixer comfort (Eppendorf AG, Germany). Once finished, the samples were centrifuged at $4000 \mathrm{~g}$ for $10 \mathrm{~min}$ and $4{ }^{\circ} \mathrm{C}$. The supernatant was transferred to a new tube and stored at $-20^{\circ} \mathrm{C}$ until use.

\section{4. $q P C R$}

All qPCR experiments were performed in $20 \mu \mathrm{L}$ with the following components: $10 \mu \mathrm{L}$ of Maxima Probe/ROX qPCR Master Mix (Thermo Fisher Scientific Inc., Waltham, MA, USA), $100 \mathrm{nM}$ primers and $150 \mathrm{nM}$ probe for phage assays, and $2 \mu \mathrm{L}$ of template. The thermal profile selected consisted of $2 \mathrm{~min}$ at $50{ }^{\circ} \mathrm{C}$ for Uracil-DNA Glycosylase (UDG) treatment (to avoid carryover contamination), followed by $10 \mathrm{~min}$ at 95 ${ }^{\circ} \mathrm{C}$ hot-start polymerase activation, and 40 cycles of dissociation at 95 ${ }^{\circ} \mathrm{C}$ for $15 \mathrm{~s}$ and annealing-extension at $63^{\circ} \mathrm{C}$ for $60 \mathrm{~s}$.

\subsection{Evaluation of the efficiency and limit of detection of the PAA-qPCR}

The assessment of the efficiency of the PAA-qPCR was determined by performing ten-fold serial dilutions of pure vB_SenS_PVP-SE2DNA in Tris-EDTA $1 \mathrm{X}$ (TE, $10 \mathrm{mM}$ Tris-HCl, $1 \mathrm{mM}$ EDTA, Sigma-Aldrich, St. Louis, USA). All dilutions were analyzed in duplicate, as described in M \&M 2.4 .

The limit of detection (LoD) of the PAA-qPCR for pure viruses was evaluated by performing ten-fold dilutions of $\mathrm{vB}$ _SenS_PVP-SE2 2 phages in BPW, and $2 \mu \mathrm{L}$ of each dilution were directly analyzed, as described in M\&M 2.4. The phage stock (dilution 0) was diluted 1:2 and this was used as the highest concentration.

\subsection{Spiked sample preparation}

Forty-one raw chicken breast samples, purchased from local supermarkets, were processed as follows: $25 \mathrm{~g}$ were weighed and $225 \mathrm{~mL}$ of $37^{\circ} \mathrm{C}$ pre-warmed BPW were added, the matrix was homogenized for $30 \mathrm{~s}$ in a Stomacher 400 Circulator (Seward Limited, West Sussex, UK); then $1 \mathrm{~mL}$ of the appropriate dilution of $S E$ (Table 1), prepared as mentioned above, was added and homogenized again for $30 \mathrm{~s}$. This matrix was incubated for $3 \mathrm{~h}$ at $37{ }^{\circ} \mathrm{C}$ with agitation $(120 \mathrm{rpm})$. After this initial incubation step, $10^{3}-10^{4} \mathrm{pfu} / \mathrm{mL}$ vB_SenS_PVP-SE2 phages were added (concentration selected after evaluation of pure phage LoD). After carefully mixing, $1 \mathrm{~mL}$ was taken, being this the time 0 (T0) sample. The matrix was re-incubated, and additional samples were withdrawn after $3 \mathrm{~h}$ and $6 \mathrm{~h}$.

Every aliquot was processed as described above in M\&M 2.3 and in M\&M 2.4. The PAA-qPCR cycle of quantification (Cq) values obtained after each incubation time (T3 and T6) were compared against $\mathrm{T} 0$ so that a Cq reduction would be related to an increase in phages' DNA, associated with their replication in viable bacteria after infection.

Table 1

Samples inoculated with $S$. Enteritidis.

\begin{tabular}{lll}
\hline Number of samples & Inoculum level $(\mathrm{cfu} / 25 \mathrm{~g})$ & Result \\
\hline $10^{*}$ & 8 & + \\
3 & $5 / 10 / 9^{* *}$ & $+/+/$ ** $^{*}$ \\
5 & $5.2 \times 10 / 9.8 \times 10 / 9.4 \times 10 /{ }^{\mathrm{a}} 8.6 \times 10$ & $+/+/++^{\mathrm{a}}$ \\
5 & $5.2 \times 10^{2} / 9.8 \times 10^{2} / 9.4 \times 10^{2} /{ }^{\mathrm{a}} 8.6 \times 10^{2}$ & $+/+/+/+^{\mathrm{a}}$ \\
2 & $9.8 \times 103$ & + \\
2 & $9.8 \times 10^{4}$ & + \\
2 & $9.8 \times 10^{5}$ & + \\
6 & 0 & - \\
2 & b $8.0 \times 10^{7}$ & - \\
2 & b $8.0 \times 10^{5}$ & - \\
2 & b $8.0 \times 10^{3}$ & - \\
\hline
\end{tabular}

*10 samples spiked for LoD evaluation.

**ND by PAA-qPCR.

${ }^{\mathrm{a}}$ Two samples were spiked with the specified concentration.

${ }^{\mathrm{b}}$ Concentration of non-viable bacteria. 


\subsection{Confirmation of viability}

In order to verify that the proposed methodology only detected viable $S E$, 6 additional samples were spiked with dead $S E$. Non-viable SE were obtained as follows: fresh pure cultures were ten-fold serially diluted and plated to determine viable counts, afterwards were autoclaved for $30 \mathrm{~min}$ at $121{ }^{\circ} \mathrm{C}$ to completely inactivate the bacteria. Once the treatment was completed, $10^{3} 10^{5}$ and $10^{7} \mathrm{cfu} / \mathrm{mL}$ of dead bacteria were added to the corresponding food sample, and processed as described above.

\subsection{Evaluation of the PAA-qPCR method}

The method was evaluated considering the LoD of SE and the following performance parameters: relative sensitivity, specificity and accuracy (SE, SP and AC), positive and negative predictive values (PPV and NPV), the kappa index of concordance $(k)$ and the acceptability limit (AL). These parameters were determined by comparing the results obtained with the expected values (positive for samples spiked with viable $S E$, and negative for non-spiked, or spiked with dead bacteria).

The evaluation of the LoD consisted on the determination of the lowest detectable concentration of $S E$. To this end, 10 chicken samples were spiked with low bacterial concentrations, typically $\leq 10 \mathrm{cfu} / 25 \mathrm{~g}$ and the procedure described in M\&M 2.5 was followed. In order to be accepted, $90 \%$ of positive samples would have to be detected, i.e. 9 out of 10 positive samples.

Regarding the other parameters, after analysis, all samples were classified as Positive or Negative Agreement if the obtained results matched those expected (PA and NA), and Positive or Negative Deviations if the results did not match (PD and ND). With these values, the performance parameters were calculated as described in previous studies (Anderson et al., 2011; D'Agostino et al., 2016; Tomas, Rodrigo, Hernandez, \& Ferrus, 2009).

\section{Results}

\subsection{Evaluation of the efficiency and limit of detection of the PAA-qPCR}

Pure phage DNA was ten-fold serially diluted, and consistent detection was achieved from $2.2 \mathrm{ng} / \mu \mathrm{L}$ to $0.22 \mathrm{fg} / \mu \mathrm{L}$, covering eight orders of magnitude, with an amplification efficiency of $98 \%$ and a correlation coefficient of 0.999 . When the same experiment was performed with pure phages, which were directly loaded into the corresponding qPCR wells, the detection was possible from $6.6 \times 10^{11} \mathrm{pfu} / \mathrm{mL}$ down to $1.3 \times 10^{3} \mathrm{pfu} / \mathrm{mL}$, being obtained an amplification efficiency of $99 \%$ with a correlation coefficient of 0.995 . These results are graphically presented in Fig. 1a and b. Based on these results, and keeping in mind that the LoD of pure phages was $10^{3} \mathrm{pfu} / \mathrm{mL}$, it was decided to add a

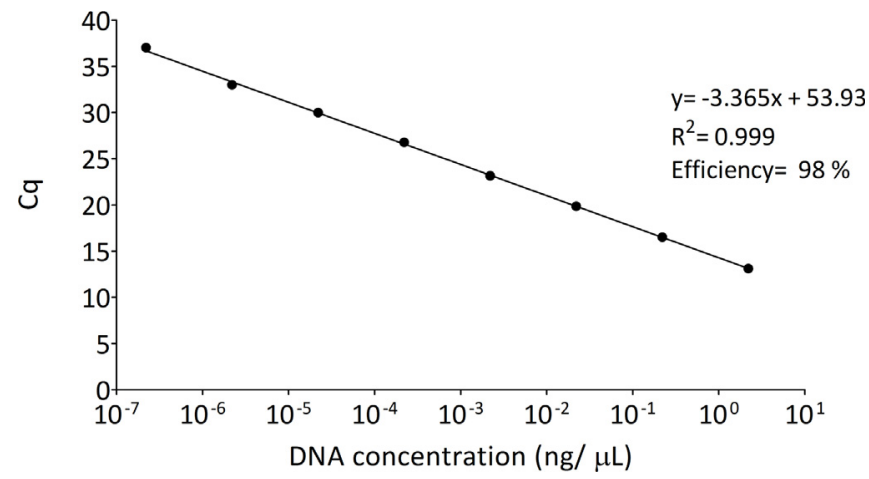

Fig. 1. a) Efficiency of the amplification obtained after ten-fold serially diluting pure phage vB_SenS_PVP-SE2 DNA. b) Amplification efficiency obtained after directly loading phages as the template, without prior DNA extraction.

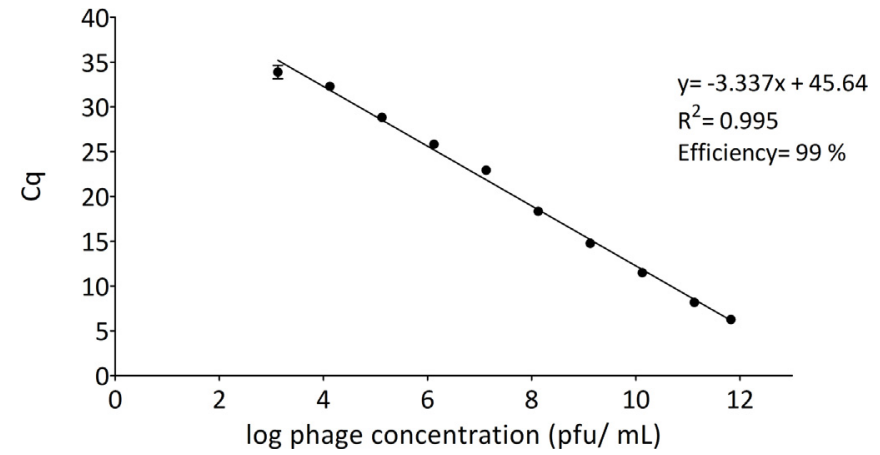

Fig. 1. (continued)

final concentration of $10^{3}-10^{4} \mathrm{pfu} / \mathrm{mL}$ to each sample.

\subsection{Confirmation of viability}

The inoculation of the food samples with non-viable microorganisms, even at the highest concentration $\left(10^{7} \mathrm{cfu} / \mathrm{mL}\right)$ did not obtain any positive result (interpreted as $\mathrm{Cq}$ variation after incubation with the phages). This simple experiment demonstrates that the proposed methodology only detected viable $S E$.

\subsection{Evaluation of the PAA-qPCR method}

The LoD of the method was determined to be $<10 \mathrm{cfu} / 25 \mathrm{~g}$ for a total time of analysis of $10 \mathrm{~h}$, which included $3 \mathrm{~h}$ of pre-enrichment, $6 \mathrm{~h}$ of co-incubation and $1 \mathrm{~h}$ of DNA enrichment and qPCR analysis.

The viable plate counts indicated that the actual value was $8 \mathrm{cfu} /$ $25 \mathrm{~g}$, but concentrations down to $5 \mathrm{cfu} / 25 \mathrm{~g}$ could also be detected (Table 1). It was also observed that, if the bacterial concentration was high $\left(10^{2}-10^{3} \mathrm{cfu} / 25 \mathrm{~g}\right)$, the detection of $S \mathrm{E}$ could be performed after $3 \mathrm{~h}$ of co-incubation, as shown in Fig. 2. Thus, the total analysis time could be reduced to $7 \mathrm{~h}$.

The evaluation of the other performance parameters, based on the results obtained from 41 spiked samples, and after $6 \mathrm{~h}$ of co-incubation, revealed values of $96.6 \%, 100 \%$ and 97.6 for the SE, SP and AC respectively. Regarding the PPV and NPV, the values obtained were $100 \%$ and $92.3 \%$ respectively. The AL values obtained were $1-1$, and most importantly, the $\kappa$, which measures the degree of agreement with the expected results, was 0.94 (1.0 maximum). Only one ND was observed, being this from a sample spiked with $9 \mathrm{cfu} / 25 \mathrm{~g}$. No positive results were obtained from any of the negative samples, including those inoculated with different concentrations $\left(10^{3}-10^{7} \mathrm{cfu} / 25 \mathrm{~g}\right)$ of non-viable microorganisms, demonstrating the specificity of the assay, and that, as

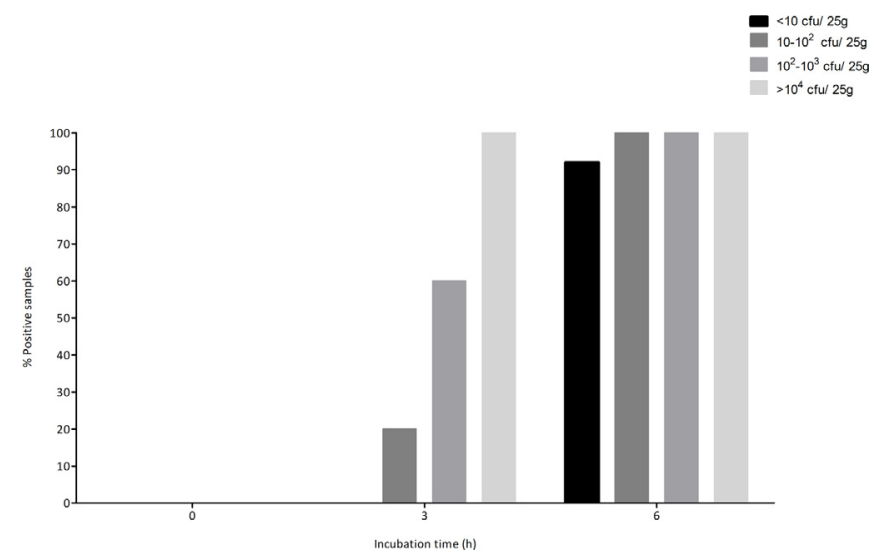

Fig. 2. Percentage of positive samples at different co-incubation times, after bacteriophage addition. 
expected, only viable $S E$ would be detected. These results are summarized in Table 1.

\section{Discussion}

In 2015, serovar Enteritidis remained as one of the most reported serovars among all Salmonella identified, representing $45.7 \%$ of all the identified human cases. Additionally, the highest occurrence of samples non-compliant with Salmonella criteria was found in foods of meat origin that were intended to be cooked before consumption, having "minced meat and meat preparations from poultry" which represents a notable level of non-compliance, among the foodstuffs analyzed (EFSA and ECDC, 2017). These data indicate that new methods, which could allow faster detection of these pathogens, are needed. Phages have been previously applied for the detection of pathogenic microorganisms, particularly for slow-growing such as Mycobacterium (Botsaris et al., 2010). Different approaches have been reported, such as plaque assays, PCR/qPCR, bioluminescent reporters, among others (Alanis Villa, Griffiths, \& Kropinski, 2014; Botsaris, Liapi, Kakogiannis, Dodd, \& Rees, 2013; Brovko, Anany, \& Griffiths, 2012; Reiman et al., 2007). These studies highlight that phages might be a promising tool for the detection of foodborne pathogens, but their application in combination with qPCR has been so far scarce. Thus, in the current study, a method which combined both, was developed and evaluated for the fast and specific detection of viable Salmonella Enteritidis in chicken samples.

In the evaluation of the LoD with pure phage DNA, $0.22 \mathrm{fg}$ were detected, covering eight consecutive dilutions as shown in Fig. 1a. Regarding the direct analysis of phage particles, without any specific DNA extraction, it was observed that down to $10^{3} \mathrm{pfu} / \mathrm{mL}$ could be reliably detected, being this value achieved covering 10 consecutive dilutions, as depicted in Fig. 1b. These data allowed to determine a qPCR amplification efficiency of 98 and 99\% respectively, both with high $\mathrm{R}^{2}$ values (0.999 and 0.995). These results are comparable to others previously reported for phage DNA detection, even though our results for the direct detection of viral particles resulted 100 times higher (Sergueev, He, Borschel, Nikolich, \& Filippov, 2010). Nonetheless, these differences did not affect the final performance of the proposed PAA-qPCR assay, as discussed below.

For food analyses, a simple thermal lysis protocol was performed before qPCR detection. This step was intended to release all the phage DNA (either free or inside phage capsids), which could be inside bacterial cells that did not complete the lytic cycle. Additionally, this was expected to increase the sensitivity of the assay. It was observed that a LoD of $8.0 \mathrm{cfu}$ of $S \mathrm{E}$ in $25 \mathrm{~g}$ was obtained in just $6 \mathrm{~h}$ of co-incubation of the contaminated samples with the phage solution. Considering the initial pre-enrichment step, an overall enrichment of $9 \mathrm{~h}$ was enough to detect bacterial concentrations below $10 \mathrm{cfu} / 25 \mathrm{~g}$ (higher concentrations can be detected in shorter periods of time). This is a significant time reduction compared with other methodologies that detect Salmonella directly but are intended for "next-day" analysis (GarridoMaestu, Chapela, Peñaranda, \& Cabado, 2015; Rodríguez-Lázaro et al., 2014). It is worth to mention that a pre-enrichment step of $3 \mathrm{~h}$ was included in our protocol, in order to allow the bacteria to "recover", however this step may be shortened, as reported in other methodologies, which just give $1 \mathrm{~h}$ for this purpose (i.e. ISO methodology for the enumeration of Listeria monocytogenes), thus allowing the complete protocol to be performed in $8 \mathrm{~h}$ (including DNA extraction and qPCR analysis). In this sense, depending on work shifts, the presented method may be implemented for self-monitoring in the food industry, allowing "same-day" detection, which represent a very interesting advantage when compared to the standard, or other rapid methods, that usually require between 20 and $48 \mathrm{~h}$.

In the present study, a total of 41 samples were analyzed, with only 1 ND observed, being this associated with a sample inoculated very close to the LoD ( $9 \mathrm{cfu} / 25 \mathrm{~g}$ ). This resulted in values greater than $92 \%$, of the performance parameters evaluated, being of particular interest the $\mathrm{k}$. For this parameter, a value of 0.94 was calculated, being interpreted in the range of $0.81-1.00$, which corresponds to "almost complete concordance" (Altman, 1991; Anderson et al., 2011). Additionally, the AL values for "ND-PD" and "ND + $\mathrm{PD}^{\prime \prime}$ were both 1 , below 3 and 6, and thus within the limits of acceptability for sensitivity as an alternative method (D'Agostino et al., 2016; ISO, 2016a, 2016b).

To confirm that the phages only infected viable $S E$, and no other microorganism, 6 samples were spiked with three different concentrations of non-viable $S E$. As expected, no positive results were obtained, thus confirming the specificity of the assay to detect only viable $S E$.

In the current study, an ISO-compatible enrichment broth, BPW, was selected. Keeping in mind that only viable $S E$ are detected, and that the phage concentration added is not enough to completely eliminate all target microorganism, all positive samples are susceptible of being confirmed following standard culture techniques, such as ISO 6579 (Gianfranceschi et al., 2014; ISO, 2003). Over the development of the current method, it was observed that direct plating of BPW enrichments on XLD not always allowed to isolate typical colonies due to the high number of interfering microorganisms. Thus, if confirmation by a classic culture method is to be performed, it would be advisable to use a culture technique that allows reducing of non-target bacteria, while increasing the number of Salmonellae.

Future studies will focus on alternatives to provide even faster detection. In this sense, finding phages with shorter latent periods (timing of phage-induced host cell lysis) will allow to reduce the time of analysis significantly. Additionally, the replacement of the enrichment broth, BPW, for an alternative medium capable of enhancing the growth of Salmonella while inhibiting, or limiting, the growth of nontarget interfering microorganisms will also allow a reduction in the time of analysis. This is also critical in order to assure the stability and infectivity of the phages. In this sense, careful attention must be taken in the storage conditions of the viruses, as if not done properly, may lose infectivity and so jeopardizing the final outcome of the assay. Finally, to expand the applicability of the proposed methodology, the selection of a phage cocktail, composed of Salmonella phages with different specificities, will be of particular interest. This phage cocktail will allow detecting Salmonella spp. instead of just one serovar, and at the same time will overcome the limitation of the appearance of strains resistant to the infection by one particular phage (Bai, Kim, Ryu, \& Lee, 2016; Santander \& Robeson, 2007).

\section{Conclusions}

The proposed methodology has demonstrated the capacity to detect viable $S E$, even at very low concentrations, in about $10 \mathrm{~h}$ including sample treatment, DNA extraction, and qPCR analysis, thus representing a significant reduction with respect to other culture-based, and molecular biology based methods. Due to the high confidence of the results obtained, this method can be suitable for the implementation on routine laboratories.

\section{Acknowledgements}

This work was supported by the project Nanotechnology Based Functional Solutions (NORTE-01-0145-FEDER-000019), supported by Norte Portugal Regional Operational Programme (NORTE2020), and by the "NanoBioSensor: Desenvolvimento de nanosensores para avaliação da qualidade microbiológica de produtos à base de fruta" (POCI-010247-FEDER-033925), supported by the Operational Thematic Program for Competitiveness and Internationalization (POCI), under the PORTUGAL 2020 Partnership Agreement, through the European Regional Development Fund (ERDF).

\section{References}

Alanis Villa, A., Griffiths, M. W., \& Kropinski, A. M. (2014). Rapid detection of Vibrio 
parahaemolyticus using bacteriophage and real-time PCR. The University of Guelph. Altman, D. G. (1991). In C, \& Hall (Eds.). Practical statistics for medical research (New York).

Anderson, A., Pietsch, K., Zucker, R., Mayr, A., Muller-Hohe, E., Messelhausser, U., .. Huber, I. (2011). Validation of a duplex real-time PCR for the detection of Salmonella spp. in different food products. Food Analytical Methods, 4(3), 259-267.

Andrews, W. H., Jacobson, A., \& Hammack, T. (2011). Salmonella. FDA, bacteriological analytical manual online. https://doi.org/Chapter5.

Bai, J., Kim, Y. T., Ryu, S., \& Lee, J. H. (2016). Biocontrol and rapid detection of foodborne pathogens using bacteriophages and endolysins. Frontiers in Microbiology, 7(APR), 1-15. https://doi.org/10.3389/fmicb.2016.00474.

Bio-Qiagen, C. L. C. (2016). CLC sequence viewer. Denmark: Aarhus.

Botsaris, G., Liapi, M., Kakogiannis, C., Dodd, C. E. R., \& Rees, C. E. D. (2013). Detection of Mycobacterium avium subsp. paratuberculosis in bulk tank milk by combined phagePCR assay: Evidence that plaque number is a good predictor of MAP. International Journal of Food Microbiology, 164(1), 76-80. https://doi.org/10.1016/j.ijfoodmicro. 2013.03.023.

Botsaris, G., Slana, I., Liapi, M., Dodd, C., Economides, C., Rees, C., et al. (2010). Rapid detection methods for viable Mycobacterium avium subspecies paratuberculosis in milk and cheese. International Journal of Food Microbiology, 141(SUPPL), S87-S90. https:// doi.org/10.1016/j.ijfoodmicro.2010.03.016.

Brovko, L. Y., Anany, H., \& Griffiths, M. W. (2012). (1st ed.). Bacteriophages for detection and control of bacterial pathogens in food and food-processing environment. Advances in food and nutrition research67Elsevier Inchttps://doi.org/10.1016/B978-0-12-3945983.00006-X.

Chapela, M., Garrido-Maestu, A., \& Cabado, A. G. (2015). Detection of foodborne pathogens by qPCR: A practical approach for food industry applications. Cogent Food Agric, 1, 1-19. https://doi.org/10.1080/23311932.2015.1013771.

D'Agostino, M., Robles, S., Hansen, F., Ntafis, V., Ikonomopoulos, J., Kokkinos, P., ... Cook, N. (2016). Validation of a loop-mediated amplification/ISO 6579-based method for analysing soya meal for the presence of Salmonella enterica. Food Analytical Methods. https://doi.org/10.1007/s12161-016-0602-7.

D'Urso, O. F., Poltronieri, P., Marsigliante, S., Storelli, C., Hernandez, M., \& RodriguezLazaro, D. (2009). A filtration-based real-time PCR method for the quantitative detection of viable Salmonella enterica and Listeria monocytogenes in food samples. Food Microbiology, 26(3), 311-316.

EFSA and ECDC (2017). The Euroean Union summary report on trends and sources of zoonsoes, zoonotic agents and food-borne outbreaks in 2015. EFSA Journal, 13(November)https://doi.org/10.2903/j.efsa.2016.4634.

Feng, K., Hu, W., Jiang, A., Sarengaowa, Xu, Y., Zou, Y., ... Wang, X. (2016). A dual filtration-based multiplex PCR method for simultaneous detection of viable Escherichia coli O157:H7, Listeria monocytogenes, and Staphylococcus aureus on fresh cut cantaloupe. PLoS One, 11(12), e0166874. https://doi.org/10.1371/journal.pone. 0166874.

Garrido-Maestu, A., Chapela, M.-J., Peñaranda, E., \& Cabado, A. G. (2015). Re-evaluation of enhanced qPCR prevalidated method for next-day detection of Salmonella spp., Shigella spp., Escherichia coli $\mathrm{O} 157$ and Listeria monocytogenes. Food Biotechnology, 29(4), 317-335. https://doi.org/10.1080/08905436.2015.1091977.

Gianfranceschi, M. V., Rodriguez-Lazaro, D., Hernandez, M., Gonzalez-Garcia, P., Comin, D., Gattuso, A., ... Prencipe, V. (2014). European validation of a Real-Time PCR-based method for detection of Listeria monocytogenes in soft cheese. International Journal of Food Microbiology, 184, 128-133.
Grimont, P. A. D., \& Weill, F. X. (2007). Antigenic formulae of the Salmonella serovars. Institute Pasteur. Retrieved from http://nih.dmsc.moph.go.th/aboutus/media/ antigenic formula of Salmonella.pdf.

ISO (2003). Microbiology of food and animal feeding stuffs - Horizontal method for the detection of Salmonella spp.

ISO (2016a). ISO 16140-1:2016 Microbiology of the food chain — method validation — Part 1. Vocabulary.

ISO (2016b). ISO 16140-2:2016 Microbiology of the food chain — method validation — Part 2: Protocol for the validation of alternative (proprietary) methods against a reference method.

Kutin, R. K., Alvarez, A., \& Jenkins, D. M. (2009). Detection of Ralstonia solanacearum in natural substrates using phage amplification integrated with real-time PCR assay. Journal of Microbiological Methods, 76(3), 241-246. https://doi.org/10.1016/j.mimet. 2008.11.008.

Reiman, R. W., Atchley, D. H., \& Voorhees, K. J. (2007). Indirect detection of Bacillus anthracis using real-time PCR to detect amplified gamma phage DNA. Journal of Microbiological Methods, 68(3), 651-653. https://doi.org/10.1016/j.mimet.2006.11. 004.

Rodríguez-Lázaro, D., Gonzalez-García, P., Delibato, E., De Medici, D., GarcÃía-Gimeno, R. M., Valero, A., et al. (2014). Next day Salmonella spp. detection method based on real-time PCR for meat, dairy and vegetable food products. International Journal of Food Microbiology, 184, 113-120.

Santander, J., \& Robeson, J. (2007). Phage-resistance of Salmonella enterica serovar Enteritidis and pathogenesis in Caenorhabditis elegans is mediated by the lipopolysaccharide. Electronic Journal of Biotechnology, 10(4), 627-632. https://doi.org/10 2225/vol10-issue4-fulltext-14.

Schmelcher, M., \& Loessner, M. J. (2014). Application of bacteriophages for detection of foodborne pathogens. Bacteriophage, 4(2), e28137. https://doi.org/10.4161/bact. 28137.

Sergueev, K. V., He, Y., Borschel, R. H., Nikolich, M. P., \& Filippov, A. A. (2010). Rapid and sensitive detection of Yersinia pestis using amplification of plague diagnostic bacteriophages monitored by real-time PCR. PLoS One, 5(6)https://doi.org/10.1371/ journal.pone.0011337.

Sillankorva, S., Pleteneva, E., Shaburova, O., Santos, S., Carvalho, C., Azeredo, J., et al. (2010). Salmonella Enteritidis bacteriophage candidates for phage therapy of poultry. Journal of Applied Microbiology, 108(4), 1175-1186. https://doi.org/10.1111/j.1365 2672.2009.04549 x.

Stewart, G. S., Jassim, S. A., Denyer, S. P., Newby, P., Linley, K., \& Dhir, V. K. (1998). The specific and sensitive detection of bacterial pathogens within $4 \mathrm{~h}$ using bacteriophage amplification. Journal of Applied Microbiology, 84(5), 777-783. https://doi.org/10. 1046/j.1365-2672.1998.00408.x.

Tomas, D., Rodrigo, A., Hernandez, M., \& Ferrus, M. A. (2009). Validation of real-time PCR and enzyme-linked fluorescent assay-based methods for detection of Salmonella spp. in chicken feces samples. Food Analytical Methods, 2(3), 180-189.

Untergasser, A., Cutcutache, I., Koressaar, T., Ye, J., Faircloth, B. C., Remm, M., et al. (2012). Primer3-new capabilities and interfaces. Nucleic Acids Research, 40(15) e115-e115.

Zhang, G., Brown, E. W., \& González-Escalona, N. (2011). Comparison of real-time PCR, reverse transcriptase real-time PCR, loop-mediated isothermal amplification, and the FDA conventional microbiological method for the detection of Salmonella spp. in produce. Applied and Environmental Microbiology, 77(18), 6495-6501. https://doi. org/10.1128/AEM.00520-11. 